\title{
Quarenta centímetros quadrados, de Samanta Schweblin
}

\author{
Nylcéa Pedra \\ Rafael Ginane Bezerra
}

Minha sogra quer que eu compre aspirinas. Me dá duas notas de dez e me indica como chegar à farmácia mais próxima.

- Você tem certeza de que não se incomoda?

Digo que não e vou em direção à porta. Tento não pensar na história que acaba de me contar, mas o apartamento é pequeno. Preciso desviar tantos móveis, tantas prateleiras e armários cheios de enfeites, que é difícil pensar em outra coisa. Saio do apartamento para o corredor escuro. Não acendo as luzes, prefiro que a luz chegue por si mesma quando as portas do elevador se abrirem.

Minha sogra montou uma árvore de Natal em cima da lareira. É uma lareira a gás, de pedras artificiais, que insiste em levar consigo cada vez que muda de apartamento. A árvore de Natal tem a altura de um anão, é magra e de um verde claro artificial. Tem bolas vermelhas, duas guirlandas douradas e seis papais-noéis pendurados nos galhos, como em um jogo de forca. Ao vê-la várias vezes ao dia, me detenho, ou penso nela enquanto faço outras coisas. Penso que minha mãe comprava guirlandas mais bem feitas e delicadas, e que os olhos dos papais-noéis não estão pintados exatamente sobre os relevos oculares onde deveriam estar.

Quando chego à farmácia que me indicou, vejo que está fechada. São dez e quinze da noite e vou ter que procurar alguma de plantão. Não conheço o bairro e não quero ligar para o Mariano, então adivinho pelo trânsito a avenida mais próxima e caminho em direção a ela. Tenho que voltar a me acostumar com essa cidade. 
Antes de viajar para a Espanha, devolvemos o apartamento que alugávamos e embalamos as coisas que não levaríamos. Minha mãe trouxe caixas do seu trabalho, quarenta e sete caixas de vinhos de Mendoza, que fomos montando à medida que precisávamos. As duas vezes em que Mariano nos deixou sozinhas, minha mãe voltou a me perguntar por que realmente estávamos indo, mas em nenhuma das vezes pude responder. Um caminhão de mudanças levou tudo até um depósito. Me lembro disso porque estou quase certa de que na caixa que diz "banheiro" tem uma cartela de aspirinas. Mas agora, de volta à Buenos Aires, ainda não fomos buscá-las. Antes, é preciso encontrar um novo apartamento, e antes ainda, é preciso recuperar um pouco do dinheiro que perdemos.

Há pouco, minha sogra me contou uma história horrível, mas contou orgulhosa. Disse que alguém deveria escrevê-la. É anterior ao seu divórcio, à venda da casa e à sua ajuda com o dinheiro para a Espanha. Depois caiu a sua pressão, teve uma terrível dor de cabeça e me mandou comprar aspirinas. Ela acha que eu sinto saudades da minha mãe e não entende porque eu não quero ligar para ela.

Uma quadra adiante, na avenida, vejo uma farmácia. Espero o semáforo para atravessar. Também está fechada, mas tem uma lista das farmácias de plantão. Se não me engano, tem uma do outro lado da Santa Fé, passando a estação Carranza. São umas quatro quadras e já me distanciei bastante. Penso que seria bom que Mariano chegasse, que perguntasse à sua mãe por mim, e ela tivesse que explicar-se, dizendo que tinha me mandado comprar aspirinas às dez e meia da noite, em um bairro que não conheço. Depois me pergunto por que seria bom.

A primeira coisa que a minha sogra me contou foi que estava de pé, no meio da sala da sua casa. Seu marido estava no trabalho, mas voltaria logo. Seus quatro filhos também estavam fora, um trabalhando com o pai, os outros estudando. $\mathrm{Na}$ noite anterior, tinha brigado outra vez com o marido e tinha pedido o divórcio. A casa era grande e tinha perdido o controle sobre ela. Agora, a mulher que limpava tinha responsabilidade sobre a casa, e minha sogra não sabia mais o que estava guardado nos armários, nem o que faltava na despensa. Quando se sentavam à mesa, os filhos se divertiam vendo-a comer. Se tinha frango, roía os ossos com ansiedade. Se tinha sobremesa, se servia duas vezes. Tomava água com a boca cheia. É porque estou muito sozinha e meus filhos só acreditam no pai, pensava consigo.

Pego a primeira rua em direção ao cruzamento, mas está fechada. É uma rua sem saída. O mesmo acontece na quadra seguinte. Procuro a quem perguntar. Encontro uma mulher que me olha desconfiada. Diz que a duas quadras mais para frente é possível passar para o outro lado da Santa Fé pelos túneis do metrô. 
Então, naquele dia, minha sogra estava de pé no meio da sala, olhou as próprias mãos e tomou uma decisão. Pegou o casaco, a carteira e saiu de casa. Pegou um táxi até a rua Liberdad. Caía um dilúvio, mas sentia que se não fizesse o que tinha que fazer naquele momento, não faria nunca mais. Quando desceu, molhou as sandálias. A água chegava até os seus tornozelos. Tocou a campainha de uma loja de compra e venda de ouro. Viu o vendedor se aproximar entre as vitrines iluminadas. Imagino que abriu a porta olhando-a de cima a baixo, lamentando que alguém tão ensopado entrasse em sua loja. Dentro, batendo em sua nuca, o ar condicionado estava muito forte.

- Quero vender esta aliança - disse ela. Pensou que seria difícil tirá-la, porque tinha engordado muito. Mas estava encharcada e a aliança saiu sem esforço.

O homem a colocou numa pequena balança eletrônica.

- Posso dar trinta dólares.

Ela levou alguns segundos para responder. Depois disse:

- É a minha aliança de casamento.

E o homem disse:

-É o que vale.

Agora desço pela boca do metrô e pego o túnel para cruzar a avenida. Diante dos cartazes de bifurcação, reconheço o lugar. Me lembro que já estive aqui outras vezes. À direita, descendo mais duas escadas, está o ponto do metrô. À esquerda, está a saída. Talvez por pensar que há alguma farmácia no metrô, ou porque quero me lembrar um pouco mais da estação, desço à direita. Gasto o tempo porque me ajuda a seguir adiante. Faz um mês e meio que não tenho absolutamente nada para fazer. É dessa maneira que vou até a estação. Levo comigo um bilhete que ainda está válido. Um trem está chegando. As rodas rangem um pouco e as portas se abrem em uníssono. Tem pouca gente na plataforma porque o serviço termina às onze. Vindo do primeiro vagão, alguém se aproxima. Talvez alguém da segurança querendo saber se embarcarei ou não. Quando o trem se afasta, me sento em um dos bancos vazios. A estação fica em silêncio. Então, um pouco além do banco, alguma coisa se move. É um velho sentado no chão. É um mendigo. Um pouco antes dos joelhos, suas pernas terminam em dois cotocos. Olha a propaganda de shampoo que está do outro lado da via.

Minha sogra aceitou o dinheiro. Me disse que saiu acariciando o dedo anular. Lá fora, já não chovia. Mas a água ainda chegava até às lojas e as sandálias molhadas machucavam os seus pés. Uns dias mais tarde, trocaria os dólares que tinha no bolso por um par de sandálias que nunca teria coragem de usar. E 
continuaria casada mais vinte e seis anos. Me contou na sala, pintando as unhas. Disse que o dinheiro da Espanha não lhe faz falta e que podemos devolvê-lo quando quisermos. Disse que sente muita falta dos filhos, mas que sabe que estão ocupados com as suas coisas e não quer incomodá-los ligando todas as vezes que gostaria de falar com eles. Pensei que tinha que escutá-la, que era a minha obrigação, porque estava morando em sua casa e porque me culpava por já não ter sua aliança de trinta dólares. Porque insistia em preparar a comida para nós, em passar a roupa toda vez que a lavávamos, porque tinha sido tão boa comigo desde o começo. Também disse que pediu os classificados de domingo para a vizinha do $\mathrm{C}$ e que procurou por um novo apartamento para se mudar, porque o atual não lhe parecia suficientemente luminoso. Escutei porque eu não tinha mais nada para fazer e olhei para ela porque estava sentada na frente da árvore de Natal. E, finalmente, disse que adorava conversar comigo, como duas amigas, que quando era uma menina, na cozinha da sua casa, se falava de tudo, que gostaria que a sua mãe ainda estivesse com ela. Ficou um tempo calada. Tentei voltar à minha revista, mas ela disse:

- Quando peço alguma coisa a Deus, peço assim: Deus, faça o melhor que puder - e deu um longo suspiro -. Na verdade, não peço nada em particular. De tanto escutar as pessoas, aprendi que nem sempre pedem o que é melhor para elas.

E então disse que sua cabeça doía muito, que estava enjoada, e me perguntou se eu me incomodaria de ir comprar umas aspirinas.

Outro trem parte da estação. O mendigo me olha e diz:

- Você também não vai pegar nenhum?

- Preciso das minhas caixas - digo isso porque, de repente, me lembro delas e descubro o que eu quero. Por que ainda estou sentada neste banco?

Mas minha sogra disse algo mais. Uma coisa tola, que não consigo tirar da cabeça. Disse que, ao sair da loja com seus trinta dólares, não conseguia voltar para casa. Tinha dinheiro para um táxi, lembrava o seu endereço, não tinha nenhuma outra coisa para fazer, mas simplesmente não conseguia fazê-lo. Caminhou até a esquina, onde havia um ponto de ônibus. Se sentou no banco de metal e ficou ali. Olhou as pessoas. Não queria nem conseguia pensar em nada, sequer tirar uma conclusão. Só conseguia olhar e respirar porque o seu corpo o fazia automaticamente. Um tempo indefinido se cumpria de modo cíclico. O ônibus chegava e partia. O ponto ficava vazio e voltava a encher. As pessoas que esperavam sempre tinham alguma coisa. Levavam as suas coisas em bolsas, em carteiras, embaixo do braço, segurando nas mãos, apoiadas no chão entre os pés. Elas estavam ali para cuidar das suas coisas. E, em troca, suas coisas amparavam-nas. 
O mendigo sobe até o meu banco. Não entendo como ele fez isso e me assusta que seja capaz de se mover tão rápido. Tem cheiro de lixo, mas é amável. De uma sacola, tira um mapa das ruas.

- Quer as suas caixas - diz, e abre o mapa em minha direção -, mas não sabe como chegar...

Mesmo sendo um mapa velho, reconheço nele as estações de metrô da cidade. Do Retiro a Constitución e do Centro até Chacarita.

Minha sogra disse que se lembra de tudo, de tal forma que pode descrever cada uma das coisas que as pessoas levavam. Mas ela tinha as mãos vazias. E não ia a lugar nenhum. Disse que estava sentada em quarenta centímetros quadrados. Disse isso. Demorei para entender. É difícil pensar na minha sogra dizendo uma coisa assim, mesmo que tenha sido isso o que ela disse: que estava sentada em quarenta centímetros quadrados e que isso era tudo o que o seu corpo ocupava no mundo.

O mendigo me espera. Desvia por um segundo o olhar e descubro que, como os papais-noéis da árvore de Natal, tem um par de olhos desenhado nas pálpebras. Acho que deveria me levantar, que no depósito reconhecerei a caixa que preciso. Mas não posso fazer isso. Não consigo sequer me mover. Se paro, acabo vendo o espaço que o meu corpo realmente ocupa. E se olho o mapa - o mendigo o aproxima um pouco mais, como se isso fosse me ajudar -, descubro que não há nenhum lugar que eu possa lhe apontar em toda a cidade.

$*$

\section{Cuarenta centímetros cuadrados}

Mi suegra quiere que compre aspirinas. Me da dos billetes de diez y me indica cómo llegar a la farmacia más cercana.

- ¿Seguro que no te molesta ir?

Niego y voy hacia la puerta. Intento no pensar en la historia que acaba de contarme, pero el departamento es chico y hay que esquivar tantos muebles, tantas repisas y vajilleros repletos de adornos que es difícil pensar en otra cosa. Salgo del departamento al pasillo oscuro. No enciendo las luces, prefiero que la luz llegue por sí misma cuando las puertas del ascensor se abran y me iluminen.

Mi suegra armó un árbol de navidad sobre la chimenea. Es una chimenea a gas y de piedras artificiales, y ella insiste en mudarla cada vez que cambia de 
departamento. El árbol de navidad tiene la altura de un enano, es flaco y de un verde claro artificial. Tiene bochas rojas, dos guirlandas doradas y seis muñecos papanoeles colgando de las ramas como en un club de ahorcados. Me detengo a verlo varias veces al día o pienso en él mientras hago otras cosas. Pienso en que mi madre compraba guirlandas mucho más mullidas y suaves, y en que los ojos de los papanoeles no están pintados exactamente sobre los relieves oculares, donde deberían estar.

Cuando llego a la farmacia que me indicó veo que está cerrada. Son las diez y cuarto de la noche y voy a tener que buscar alguna de turno. No conozco el barrio y no quiero llamar a Mariano, así que adivino por el tránsito la avenida más cercana y camino hacia allá. Tengo que volver a acostumbrarme a esta ciudad.

Antes de viajar a España devolvimos el departamento que alquilábamos y embalamos las cosas que no llevaríamos con nosotros. Mi madre trajo cajas de su trabajo, cuarenta y siete cajas de vinos mendocinos que fuimos armando a medida que las necesitábamos. Las dos veces que Mariano nos dejó solas mi madre volvió a preguntarme por qué estábamos yéndonos realmente, pero ninguna de las veces pude contestar. Un camión de mudanzas llevó todo hasta una baulera. Me acuerdo de esto porque estoy casi segura de que en la caja que dice "baño" hay una tira de aspirinas. Pero ahora, de regreso a Buenos Aires, todavía no fuimos por ellas. Antes hay que encontrar un nuevo departamento, y antes de eso hay que juntar algo de toda la plata que perdimos.

Hace un rato mi suegra me contó esta historia horrible, pero la contó orgullosa y dijo que alguien debería escribirla. Es anterior a su divorcio, anterior a la venta de la casa y a su ayuda con el dinero para España. Después le bajó la presión, le vino ese terrible dolor de cabeza y me mandó a comprar aspirinas. Cree que extraño a mi madre, y no entiende por qué no quiero llamarla.

Veo una farmacia una cuadra más allá, sobre la avenida, espero el semáforo para cruzar. También está cerrada pero tiene una lista de turnos. Si me ubico bien hay una del otro lado de Santa Fe, pasando las vías de la estación Carranza. Son unas cuatro cuadras más y ya me alejé bastante. Pienso que sería bueno que Mariano llegara, le preguntara a su madre por mí, y ella tuviera que explicarse diciendo que me ha mandado a comprar aspirinas a las diez y media de la noche por un barrio que no conozco. Después me pregunto por qué eso sería algo bueno.

Lo primero que me contó mi suegra es que estaba de pie en medio del comedor de su casa. Su marido estaba en el trabajo, pero regresaría pronto. Sus cuatro hijos estaban fuera también, uno trabajando con el padre, los otros estudiando. La noche anterior se había peleado otra vez con su marido, y le había 
pedido el divorcio. La casa era grande, y había perdido el control sobre ella. La mujer que limpiaba estaba a cargo ahora, y ella ya no podía decir qué se guardaba en los placares ni qué faltaba en las alacenas. Cuando se sentaban en la mesa, los hijos se divertían viéndola comer. Si había pollo roía los huesos con ansiedad, si había postre se servía doble ración, tomaba agua con la boca llena. Es que estoy muy sola, pensaba para sí misma, y mis hijos solo creen en su padre.

Tomo la primera calle hacia el cruce pero está cerrada, es una calle sin salida, y lo mismo sucede en la cuadra siguiente. Busco alguien a quien preguntar. Encuentro a una mujer que me mira desconfiada. Dice que dos cuadras más allá se puede pasar al otro lado de Santa Fe por los túneles del subte.

Así que ese día mi suegra estaba de pie en medio del comedor, se miró las manos y decidió su siguiente paso. Agarró el abrigo, la cartera, salió de la casa y tomó un taxi hasta la calle Libertad. Diluviaba, pero sentía que, si no hacía lo que tenía que hacer en ese mismo momento, no iba a hacerlo nunca más. Cuando bajó se mojó las sandalias, el agua le llegaba hasta los tobillos. Tocó el timbre de un local de compra-venta de oro. Vio al vendedor acercarse entre los mostradores iluminados. Supongo que le abrió mirándola de arriba abajo, lamentando que alguien entrara a su negocio tan empapado. Adentro el aire acondicionado estaba muy fuerte y le pegaba sobre la nuca.

- Quiero vender este anillo - dijo ella. Pensó que le costaría quitárselo, porque había engordado mucho, pero estaba empapada y el anillo salió sin esfuerzo.

El hombre lo colocó en una pequeña balanza electrónica.

- Puedo darle treinta dólares.

Ella se tomó unos segundos para contestar. Después dijo:

- Es mi anillo de bodas.

Y el hombre dijo:

- Es lo que vale.

Ahora bajo por la boca del subte y tomo el túnel para cruzar la avenida. Frente a los carteles de bifurcación reconozco el lugar y me acuerdo que ya he estado aquí otras veces. A la derecha, bajando dos escaleras más, está la parada de subte, a la izquierda está la salida. Quizá porque pienso que hay alguna farmacia en el subte, o porque quiero recordar un poco más la estación, bajo hacia la derecha. Pierdo el tiempo porque me ayuda a seguir adelante, hace un mes y medio que no tengo absolutamente nada que hacer. Así que voy hacia la estación. Llevo encima una tarjeta que todavía sirve, un tren está llegando. Chillan un poco las ruedas y las puertas se abren al unísono. En el andén hay poca gente porque el servicio termina 
a las once. Alguien se asoma desde el primer vagón, tal vez alguien de seguridad preguntándose si subiré o no subiré. Cuando el tren se aleja me siento en uno de los bancos vacíos. La estación queda en silencio y entonces algo se mueve un poco más allá del banco. Es un hombre viejo sentado en el piso. Es un mendigo, sus piernas terminan en dos muñones un poco antes de las rodillas. Mira el cartel de champú que hay del otro lado de las vías.

Mi suegra aceptó el dinero, me dijo que salió acariciándose el dedo anular. Afuera ya no llovía pero el agua todavía llegaba hasta los locales y las sandalias mojadas le lastimaban los pies. Unos días más tarde cambiaría los dólares que tenía en los bolsillos por un par de sandalias que nunca tendría la fuerza de ponerse, y aun así, seguiría casada veintiséis años más. Me lo contó en el comedor pintándose las uñas. Dijo que no le hace falta el dinero de España, y que podemos devolverlo cuando queramos. Dijo que extraña mucho a sus hijos, pero sabe que ellos están ocupados con sus cosas, y no quiere ser cargosa llamándolos todas las veces que realmente querría llamarlos. Pensé que tenía que escucharla, que era mi obligación porque estaba viviendo en su casa, y porque me daba culpa que ya no tuviera su anillo de treinta dólares. Porque insistía en cocinarnos, en planchar la ropa cada vez que la lavábamos, porque conmigo había sido tan buena desde el principio. También dijo que le pidió a la vecina del C los clasificados del domingo y se fijó si no había algún nuevo departamento para mudarse, porque este tampoco le parecía lo suficientemente luminoso. La escuché porque no tenía nada más que hacer, y la miré porque estaba sentada delante del árbol de navidad. Y al fin dijo que le encantaba charlar conmigo, así, como dos amigas. Que cuando era una nena, en la cocina de su casa, se charlaba de todo, que le gustaría que su madre todavía la acompañara. Se quedó un rato callada, así que intenté volver a abrir mi revista, pero dijo:

- Cuando le pido algo a Dios pido así: Dios, vos hacé lo mejor que puedas - y dio un largo suspiro-. De verdad, no pido nada puntual. De tanto escuchar a la gente aprendí que no siempre piden lo que es mejor para ellos.

Y entonces dijo que le dolía mucho la cabeza, que estaba mareada, y me preguntó si me molestaría ir por unas aspirinas.

Otro tren se ve de la estación. El mendigo me mira y dice:

- ¿Usted tampoco toma ninguno?

- Necesito mis cajas - digo, porque de pronto me acuerdo de ellas y así es como sé qué es lo que quiero, por qué estoy sentada todavía en este banco.

Pero mi suegra dijo algo más. Algo muy tonto que ya no pude sacarme de la cabeza. Dijo que, al salir del negocio con sus treinta dólares, no podía regresar 
a su casa. Tenía dinero para un taxi, recordaba su dirección, no tenía ninguna otra cosa que hacer, pero, simplemente, no podía hacerlo. Caminó hasta la esquina, donde había una parada de colectivos, se sentó en el banco de metal, y ahí se quedó. Miró a la gente. No quería ni podía pensar en nada, ni sacar una conclusión. Solo podía mirar y respirar, porque su cuerpo lo hacía automáticamente. Un tiempo indefinido se cumplía de un modo cíclico, el colectivo llegaba y se iba, la parada se quedaba vacía, y se volvía a llenar. La gente que esperaba cargaba siempre con algo. Llevaban sus cosas en bolsos, en carteras, bajo el brazo, colgando de las manos, apoyadas en el piso entre los pies. Ellos estaban ahí para cuidar de sus cosas, y a cambio sus cosas los sostenían.

El mendigo trepa hasta mi banco. No entiendo cómo lo ha hecho, y me asusta que pueda moverse tan rápido. Huele a basura, pero es amable. Saca de su bolsa una guía de las calles.

- Quiere sus cajas - dice, y abre la guía hacia mí -, pero no sabe cómo llegar...

Aunque es una guía vieja reconozco en el mapa las estaciones de subte de la ciudad. De Retiro a Constitución, y del Centro hasta Chacarita.

Mi suegra dice que lo recuerda todo, tanto lo recuerda que puede describir cada una de esas cosas que cargaba la gente. Pero ella tenía las manos vacías. Y no iba hacia ningún lugar. Dijo que estaba sentada en cuarenta centímetros cuadrados, eso dijo. Tardé en entender. Es difícil pensar en mi suegra diciendo algo así, aunque eso es lo que dijo: que estaba sentada en cuarenta centímetros cuadrados, y que eso era todo lo que ocupaba su cuerpo en el mundo.

El mendigo me espera. Baja un segundo la mirada y descubro que en los párpados tiene dibujados un par de ojos, como los papanoeles del árbol de navidad. Creo que debería ponerme de pie, que una vez en la baulera reconoceré la caja que necesito. Pero no puedo hacerlo. No puedo siquiera moverme. Si me paro, no podré evitar ver cuánto ocupa realmente mi cuerpo. Y si miro el mapa - el mendigo lo acerca ahora un poco más, por si eso ayuda -, descubriré que, en toda la ciudad, no hay ningún sitio que pueda señalarle.

\section{Nota dos tradutores}

Samanta Schweblin (Buenos Aires, 1978) é uma das vozes mais aclamadas na literatura em língua espanhola dos últimos anos. Sua celebração é tamanha a ponto de seu nome figurar entre a lista de escritoras responsáveis pelo novo "boom" da literatura hispano-americana. Tal celebração, contudo, não parece 
despropositada. É dona de uma produção literária concisa, dos seus quatro livros publicados, três são de relatos curtos (El nucleo del disturbio, Pájaros en la boca y Siete casas vacias) e um é o romance Distancia de rescate, recente finalista do prêmio Booker Man Internacional como único representante da língua espanhola. No final de 2018, lançou o seu último romance, Kentukis. Até o momento, apenas duas de suas obras foram traduzidas para o português: Pássaros na boca e Distância de resgate.

Siete casas vacías (2015) é o seu mais recente livro de contos, merecedor do IV Prêmio Internacional de Narrativa Breve Ribera del Duero. Os sete contos que compõem a obra são um convite à inquietação. Ambientados em entornos familiares, longe de o cotidiano ser sinônimo de segurança e conforto, cada uma das sete casas-conto remete ao vazio e ao desengano. A normalidade e previsibilidade sempre rompidas de forma incômoda e surpreendente levam o leitor a visitar temas tão silenciados como a morte, o esquecimento, a doença e a solidão.

"Cuarenta centímetros cuadrados" é uma das Siete casas vacias. Melhor dizendo, é a ausência da casa, do referente, do pertencimento e da territorialidade. Em um fluxo de consciência, organizado em sequências de parágrafos que se intercalam, a narradora coloca em paralelo duas histórias: a de sua sogra, em um tempo passado, e a sua própria, em um tempo presente.

Depois de uma temporada vivendo na Espanha, a narradora retorna a Buenos Aires e passa a morar em um pequeno apartamento junto com a sogra. O pequeno espaço que poderia convidar para uma intimidade familiar, expressa inclusive na fala da sogra ao dizer que gosta do fato de conversarem como "duas boas amigas", é prontamente abandonado pela necessidade de sair comprar uma aspirina para a sua súbita dor de cabeça. A suposta intimidade vista pela sogra é, ao olhar da narradora, apenas "um sentimento de culpa por alguém que desde o começo lhe tratou tão bem" e só possível pelo fato de ela "não ter absolutamente nada o que fazer" desde que voltou.

A busca pela aspirina - metáfora para a cura da dor das personagens? vai dando passo a apresentação da narradora protagonista que, não encontrando nenhuma farmácia aberta, mas sabendo exatamente em que caixa guardava uma cartela de aspirinas no depósito no qual estavam armazenados os seus pertences, deambula pela cidade que outrora era sua, mas que agora não reconhece.

Em sua errância, reconstrói mentalmente a história que a sogra acabara de lhe contar. Por motivos diferentes, ambas compartilham a mesma impossibilidade de retorno. Com as mãos vazias, o único que se tem é a si mesmo, esse corpo desenraizado que não ocupa mais que 40 centímetros quadrados e para o qual não se pode assinalar uma localização em um mapa. 


\section{Referência bibliográfica}

SCHWEBLIN, Samanta. Cuarenta centímetros cuadrados. In.: Siete casas vacías.

Madrid: Editorial Páginas de Espuma, 2015. 